\title{
Conceptual design of multi-source CCS pipeline transportation network for Polish energy sector
}

\author{
Niccolo Isoli ${ }^{1}$, Maciej Chaczykowski ${ }^{1, *}$ \\ ${ }^{1}$ Warsaw University of Technology, Department of Building Facilities, Hydro and Environmental \\ Engineering, ul. Nowowiejska 20, 00-653 Warsaw, Poland
}

\begin{abstract}
The aim of this study was to identify an optimal CCS transport infrastructure for Polish energy sector in regards of selected European Commission Energy Roadmap 2050 scenario. The work covers identification of the offshore storage site location, $\mathrm{CO}_{2}$ pipeline network design and sizing for deployment at a national scale along with CAPEX analysis. It was conducted for the worst-case scenario, wherein the power plants operate under full-load conditions. The input data for the evaluation of $\mathrm{CO}_{2}$ flow rates (flue gas composition) were taken from the selected cogeneration plant with the maximum electric capacity of $620 \mathrm{MW}$ and the results were extrapolated from these data given the power outputs of the remaining units. A graph search algorithm was employed to estimate pipeline infrastructure costs to transport $95 \mathrm{MT}$ of $\mathrm{CO}_{2}$ annually, which amount to about $612.6 \mathrm{M} €$. Additional pipeline infrastructure costs will have to be incurred after 9 years of operation of the system due to limited storage site capacity. The results show that CAPEX estimates for $\mathrm{CO}_{2}$ pipeline infrastructure cannot be relied on natural gas infrastructure data, since both systems exhibit differences in pipe wall thickness that affects material cost.
\end{abstract}

\section{Introduction}

The long-term warming of the climate system is mainly driven by $\mathrm{CO}_{2}$ emissions, therefore the internationally agreed objective of limiting the increase in global average temperatures to well below $2^{\circ} \mathrm{C}$ above pre-industrial levels requires significant reductions in $\mathrm{CO}_{2}$ emissions. In the context of necessary reductions by developed countries as a group, the European Union member states are committed to reducing greenhouse gas emissions to $80-95 \%$ below 1990 levels by 2050 [1]. The reductions of greenhouse gas emissions will put particular pressure on energy systems, which need to be almost emission-free despite higher demand. The European Commission proposed several scenarios of energy system transformation for achieving its 2050 emissions target. In a low nuclear energy scenario, assuming that no new nuclear reactors are being built (besides reactors currently under construction), around $32 \%$ penetration of CCS in power generation has been predicted. In the case of industrial applications carbon capture and storage is expected to account even for half of the global emissions cuts required by 2050. Indeed, CCS is the only technology

\footnotetext{
* Corresponding author: maciej.chaczykowski@is.pw.edu.p1
} 
that can significantly reduce $\mathrm{CO}_{2}$ emissions from coal- and gas-fired power plants as well as from energy intensive-industries.

Until recently research objectives on CCS transport were mostly focused on predicting the cost of pipeline transport [2], while route planning received relatively less attention. Chandel et al. [3] describe the economies of scale that can be achieved for $\mathrm{CO}_{2}$ transport by collecting $\mathrm{CO}_{2}$ emissions from multiple power plants into a trunkline that pipes the emissions to a single storage site. As the $\mathrm{CO}_{2}$ flow rate that can be handled by a trunkline is increased, the levelized cost of transporting it declines exponentially. They conclude that low transportation costs over long distances open up the possibility for developing CCS systems that connect $\mathrm{CO}_{2}$ sources to far away storage sites where storage costs are relatively low. Weiths and Wiley [4] employ genetic algorithm for designing the spanning tree type CCS network. Optimal CCS network transporting $\mathrm{CO}_{2}$ from each source to at least one sink should not have loops, since recirculation would increase the pumping power required by the network, unless there is the advantage due to redundancy in parallel configuration of the pipelines. Different transport and storage options resulting in different network topology were discussed in the study of offshore $\mathrm{CO}_{2}$ transportation cases for South Korea by Zahid et al. [5] and Jung et al. [6]. $\mathrm{CO}_{2}$ transport options from coal-fired power plant to offshore storage sites near Japan's coastline, including liquefied $\mathrm{CO}_{2}$ by ship, $\mathrm{CO}_{2}$ hydrate by ship and pipeline, were studied by Suzuki et al. [7]. In the study by Jain et al. [8] greedy algorithm was used to calculate the optimal distance between the source and the sink for CCS infrastructure in eastern India. It was assumed that future pipelines for transportation of $\mathrm{CO}_{2}$ would be built along the railway network. Least cost optimisation model of an integrated $\mathrm{CO}_{2}$ capture, transportation and storage infrastructure for the UK over four time periods up to year 2050 was presented in the study by Elahi et al. [9]. The physical characteristics of a potential pipeline network for $\mathrm{CO}_{2}$ transportation in the Humber Region in the UK area have been discussed by Luo et al. [10]. Hetland et al. [11] present the status of the large European CCS demonstration projects with particular emphasis on transport systems development. The costs of 15 transport scenarios involving the use of 3 pipelines and 5 offshore storage sites in Guangdong province, China were evaluated by Bai et al. [12]. It has been concluded that cost assessment methodology during the design-price evaluation should integrate local prices. Some key design issues that must be considered for the development of large scale $\mathrm{CO}_{2}$ transportation network are reviewed in the study by Han et al. [13]. They conclude that to ensure the safe and cost-effective transportation, the concentrations of impurities in $\mathrm{CO}_{2}$ stream should be restricted in an appropriate range. Similar conclusions were drawn in the studies by Chaczykowski and Osiadacz [14] and Wetenhall et al. [15], where the effect of impurities on pumping power and transport costs was observed, regardless of the assumed network structure and geometry.

The main objective of this study is to identify an optimal group selection of power plants, which contribute $32 \%$ to national power generation capacity for achieving European Commission 2050 emissions target. The optimal selection of power plants has been made based on a tree branched pipeline network design and a capital expenditures analysis for each unit. The design-price evaluation integrates local prices. Finally, the comparison to the current natural gas infrastructure capital expenditures is made.

\section{Basic assumptions and input data}

$\mathrm{CO}_{2}$ streams for power plants have been calculated based on the analysis carried out for "Siekierki" power plant, located in Warsaw, whose flue gas composition was obtained from plant operator. A basic post combustion installation based on MEA absorption process was assumed and with the use of process simulator, taking the overall efficiency of 
$90 \%$, the flow rate of $951 \mathrm{~m}^{3} / \mathrm{h}$ of captured $\mathrm{CO}_{2}$ was predicted. The volume stream from the above plant was considered as a reference case, by looking at we have extrapolated the numbers for the other power plants. The results are presented in table 2.1

The operating pressure range of the pipeline infrastructure was set to (8-15) $\mathrm{MPa}$ in order to maintain the post combustion $\mathrm{CO}_{2}$-rich mixture in supercritical phase. As a result the pipeline wall thickness for the whole network was chosen equal to $25 \mathrm{~mm}$. X70 steel has been selected for pipe material with the density of $7850 \mathrm{~kg} / \mathrm{m}^{3}$.

Material costs are calculated based on pipeline mass [16], with the assumption of unit price of $1000 €$ per 1 tonne of X70 steel. These costs were assumed to represent $30 \%$ of total costs including assembly works.

\subsection{Power plants in Polish energy sector}

The basic parameters of major fossil fuel based power plants in Polish energy sector are presented in Table 2.1. Predicted $\mathrm{CO}_{2}$ streams are extrapolated values based upon the reference case calculations for the Siekierki power plant input data.

Table 2.1. Technical data of power plants.

\begin{tabular}{|c|c|c|c|c|c|c|}
\hline No. & Power plant & Fuel & $\begin{array}{c}\text { Power } \\
\text { MW }\end{array}$ & $\begin{array}{c}\mathrm{CO}_{2} \\
\text { stream } \\
\mathbf{m}^{3} / \mathbf{h}\end{array}$ & Latitude & Longitude \\
\hline 1 & Rogowiec & Lignite & 5298 & 8127 & $51^{\circ} 16^{\prime} 36^{\prime \prime} \mathrm{N}$ & $19^{\circ} 18^{\prime} 11 " \mathrm{E}$ \\
\hline 2 & Kozienice & Black coal & 2820 & 4326 & $51^{\circ} 35^{\prime} 08^{\prime \prime} \mathrm{N}$ & $21^{\circ} 33^{\prime} 04^{\prime \prime} \mathrm{E}$ \\
\hline 3 & N. Czarnowo & Black coal & 1984 & 3044 & $53^{\circ} 11^{\prime} 42^{\prime \prime} \mathrm{N}$ & $14^{\circ} 29^{\prime} 06^{\prime \prime} \mathrm{E}$ \\
\hline 4 & Połaniec & Black coal, Biomass & 1811 & 2778 & $50^{\circ} 25^{\prime} 57^{\prime \prime N} \mathrm{~N}$ & $21^{\circ} 16^{\prime} 50^{\prime \prime} \mathrm{E}$ \\
\hline 5 & Rybnik & Black coal & 1775 & 2723 & $50^{\circ} 05^{\prime} 55^{\prime \prime} \mathrm{N}$ & $18^{\circ} 32^{\prime} 42^{\prime \prime E}$ \\
\hline 6 & Jaworzno & Black coal, Biomass & 1535 & 2355 & $50^{\circ} 12^{\prime} 16^{\prime \prime} \mathrm{N}$ & $19^{\circ} 16^{\prime} 12^{\prime \prime} \mathrm{E}$ \\
\hline 7 & Bogatynia & Lignite & 1499 & 2300 & $50^{\circ} 54^{\prime} 27^{\prime \prime} \mathrm{N}$ & $14^{\circ} 57^{\prime} 14^{\prime \prime} \mathrm{E}$ \\
\hline 8 & Brzezie & Black coal & 1492 & 2289 & $50^{\circ} 45^{\prime} 39^{\prime \prime} \mathrm{N}$ & $17^{\circ} 52^{\prime} 30^{\prime \prime} \mathrm{E}$ \\
\hline 9 & Pątnów & Lignite & 1200 & 1841 & $52^{\circ} 18^{\prime} 27^{\prime \prime} \mathrm{N}$ & $18^{\circ} 15^{\prime} 29^{\prime \prime} \mathrm{E}$ \\
\hline 10 & Łaziska Górne & Black coal & 1155 & 1772 & $50^{\circ} 09^{\prime} 17^{\prime \prime} \mathrm{N}$ & $18^{\circ} 50^{\prime} 37^{\prime \prime} \mathrm{E}$ \\
\hline 11 & Będzin & Black coal & 820 & 1258 & $50^{\circ} 19^{\prime} 26^{\prime \prime} \mathrm{N}$ & $19^{\circ} 07^{\prime} 45^{\prime \prime} \mathrm{E}$ \\
\hline 12 & Trzebinia & Black coal & 666 & 1022 & $50^{\circ} 09^{\prime} 35^{\prime \prime} \mathrm{N}$ & $19^{\circ} 28^{\prime} 14^{\prime \prime} \mathrm{E}$ \\
\hline 13 & Ostrołęka & Black coal, Biomass & 647 & 993 & $53^{\circ} 04^{\prime} 58^{\prime \prime N}$ & $21^{\circ} 34^{\prime} 21^{\prime \prime} \mathrm{E}$ \\
\hline 14 & Wars & Black coal, Biom & 620 & 951 & $52^{\circ} 13^{\prime} 566^{\prime \prime} \mathrm{N}$ & $21^{\circ} 00^{\prime} 30^{\prime \prime} \mathrm{E}$ \\
\hline 15 & Pątnów & Lignite & 474 & 727 & $52^{\circ} 18^{\prime} 27^{\prime \prime} \mathrm{N}$ & $18^{\circ} 15^{\prime} 29^{\prime \prime} \mathrm{E}$ \\
\hline 16 & Skawina & Black coal, Biomass & 440 & 675 & $49^{\circ} 58^{\prime} 30^{\prime \prime} \mathrm{N}$ & $19^{\circ} 49^{\prime} 42^{\prime \prime} \mathrm{E}$ \\
\hline 17 & Stalowa Wola & Black coal & 330 & 506 & $50^{\circ} 34^{\prime} 34^{\prime \prime} \mathrm{N}$ & $22^{\circ} 03^{\prime} 40^{\prime \prime} \mathrm{E}$ \\
\hline 18 & Konin & Lignite & 198 & 304 & $52^{\circ} 13^{\prime} 39^{\prime \prime} \mathrm{N}$ & $18^{\circ} 15^{\prime} 41^{\prime \prime E}$ \\
\hline
\end{tabular}

\subsection{Identification of storage site}

The selected geological structure is located in northwest area of the Baltic Sea. Based on the Polish Geological Institute report [17], there are four wells in the sea that satisfy the $\mathrm{CO}_{2}$ storage criteria with total capacity of 0.9 Gt. Storage depth of the structure is $800-2800 \mathrm{~m}$ and its porosity is higher than $9 \%$.

\section{$3 \mathrm{CO}_{2}$ transmission system design}

It has been assumed that pipeline system would be used to transport dense-phase, $\mathrm{CO}_{2}$-rich mixtures from capture plants to the offshore storage site. Pipeline transportation has the 
advantages of being cost-effective and readily expandable. The $\mathrm{CO}_{2}$ pipe network, except from pipeline interconnector to the storage site, consists of tree branches running parallel to the existing natural gas transmission system infrastructure. The advantages arising from such arrangement are threefold:

1. The existing natural gas pipeline safe separation distances, i.e. the distances at which natural gas pipelines can be safely sited near a community, could be considered as beneficial in terms of $\mathrm{CO}_{2}$ pipeline risk analysis. These distances are defined in terms of the distances needed to protect against a specified heat flux from the fire. There have been limited studies to date concerning the determination of safety separation distances for $\mathrm{CO}_{2}$ pipelines. Mahgerefteh et al. [18] performed the modelling of product loss during a pipeline rupture, which is an important factor related to the establishment of a safe separation distance therefrom. Comparison of $\mathrm{CO}_{2}$ outflow data with those for the rupture of the same pipeline containing natural gas indicates a significantly greater amount of $\mathrm{CO}_{2}$ released.

2. The pumps installed in booster stations along the pipelines to compensate for the pressure losses and elevation changes and to ensure a required flow of $\mathrm{CO}_{2}$ would be able to be driven by gas turbines fuelled with natural gas, which would not require significant additional investments in gas pipeline or electricity infrastructure.

3. Linear infrastructure investment projects, such as roads, railway lines, telecommunication lines, electric power lines and pipelines for transmission of gas and petroleum products have a negative ecological effects in terrestrial and aquatic ecosystems. It is clear that the impacts associated with the use of existing infrastructure corridor would be quite different compared to those posed by newly built infrastructure.

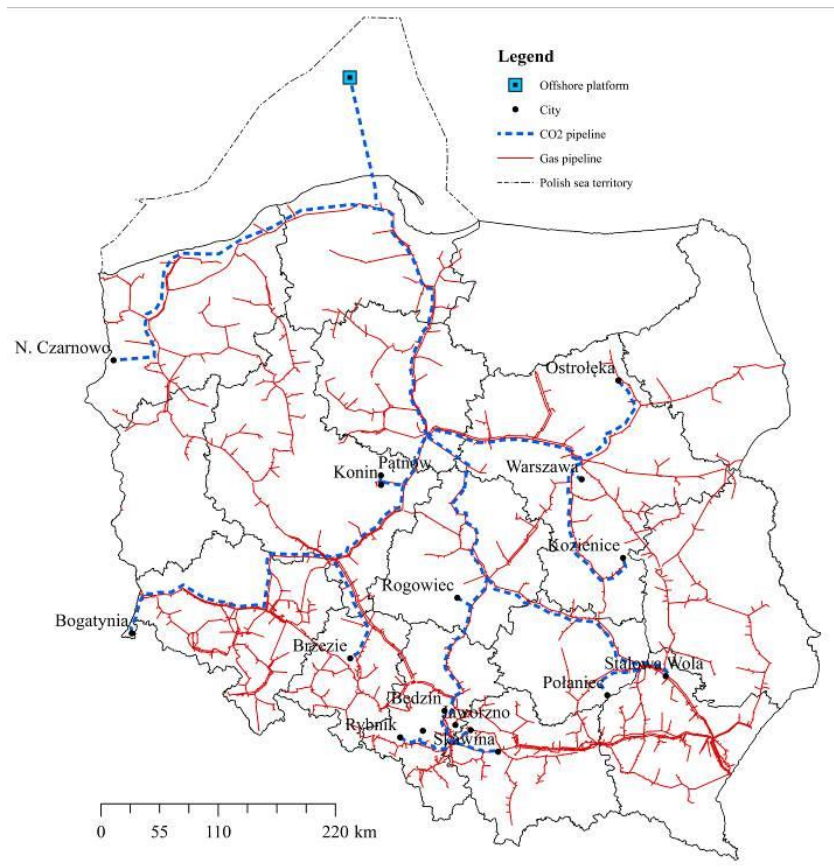

Fig. 3.1. Optimal infrastructure design including all power plants.

The capital cost of a pipeline project is largely a function of its diameter and length, although other factors, such as operating pressure, and various risk factors, are also significant. One of the challenging problems in pipeline infrastructure design calculations is the shortest path problem minimizing transport costs. Shortest path programming is 
a well-established subject in mathematics and computer science. Dijkstra's algorithm solves the single-source shortest-path problem on directed graph with a nonnegative edge weights. This algorithm was used as a subroutine in this work. However, Dijkstra's algorithm fails to form a tree that includes every specific vertex. Furthermore, optimal $\mathrm{CO}_{2}$ pipeline infrastructure parallel to the natural gas transmission system do not necessarily should have shortest paths to the storage site due to the overlapped paths that could be used as trunk lines with reduced pipe material coverage. In fact, the priority level of this requirement can be very high as in the case of data transmission applications [19]. In this study we propose the following algorithmic approach to the preliminary design of $\mathrm{CO}_{2}$ transmission system infrastructure running parallel to an existing natural gas pipeline infrastructure:

1. Determine shortest paths along existing natural gas pipelines from power plants to storage site and mark all power plants as unexamined.

2. Set the unexamined plant with the longest path as current plant, mark it as examined and save its value in a matrix of distances.

3. Find the first/next unexamined plant to the current plant by shortest path routing.

4. Shortest path from the unexamined plant to the storage site forms a subtree of the currently registered tree in a matrix of distances? Yes: Set it as current plant, mark examined and fulfil its value in a distance matrix; No: Mark the plant as examined and go to pt. 3

5. Are all the plants examined? Yes: Go to pt. 6., No: Go to pt. 3.

6. Matrix of distances completed? Yes: End; No: Mark all power plants with missing routes as unexamined and go to pt. 2. to continue with the new start point.

The results of optimal infrastructure design calculations for all power plants based on the above procedure are presented in Fig. 3.1. Given the topology of the network, appropriate diameter sizing calculations were performed using the steady state pipeline flow model from [20] with maximum flow velocity criterion of $20 \mathrm{~m} / \mathrm{s}$. The results are shown in Table 3.1 in the form of the corresponding flow weighted unit costs of the $\mathrm{CO}_{2}$ transport infrastructure for each power plant. The total transportation distance and total CAPEX for this case scenario were $2544 \mathrm{~km}$ and $2167.8 \mathrm{M}$, respectively.

Table 3.1. Transport infrastructure CAPEX for individual power plants.

\begin{tabular}{|c|c|c|}
\hline Power Plant & Total cost $(\mathrm{M} €)$ & $\begin{array}{c}\text { Flow weighted unit cost } \\
\left.\text { EUR/(m } / \mathbf{m}^{3} / \mathbf{h}\right)\end{array}$ \\
\hline Będzin & 59.3 & 45615 \\
\hline Bogatynia & 230.4 & 100193 \\
\hline Brzezie & 149.9 & 65514 \\
\hline Jaworzno & 116.2 & 45615 \\
\hline Konin & 9.6 & 31701 \\
\hline Kozienice & 274.4 & 63434 \\
\hline Łaziska Górne & 103.2 & 45615 \\
\hline N. Czarnowo & 232.9 & 76508 \\
\hline Ostrołęka & 82.6 & 83247 \\
\hline Pątnów I & 78.6 & 30578 \\
\hline Pątnów II & 18.6 & $305 / 8$ \\
\hline Połaniec & 207.5 & 74679 \\
\hline Rogowiec & 277.0 & 34091 \\
\hline Rybnik & 158.9 & 45615 \\
\hline Skawina & 45.6 & 45615 \\
\hline Stalowa Wola & 40.0 & 79195 \\
\hline Trzebinia & 59.1 & 45615 \\
\hline Warszawa & 42.3 & 44489 \\
\hline
\end{tabular}




\section{Optimal $\mathrm{CO}_{2}$ transportation network for selected 2050 EC roadmap scenario}

Mechleri et al. [21] presented an approach for the optimal design of $\mathrm{CO}_{2}$ transport pipeline. They demonstrate that where CCS plants are deployed in an energy system characterised by high share of intermittent renewable energy, the resulting displacement of CCS power plant generation by renewable energy generation leads to a decade-on-decade declining flow of $\mathrm{CO}_{2}$ through the transport infrastructure. This means that the right-sizing of $\mathrm{CO}_{2}$ transport infrastructure requires the assumption of a reduced penetration of CCS in power generation without compromising the ability to accommodate future capacity. Therefore, the realistic scenarios should assume reduced penetration of CCS in power generation sector. In this study $32 \%$ penetration of CCS in power generation as predicted in [1] is considered.

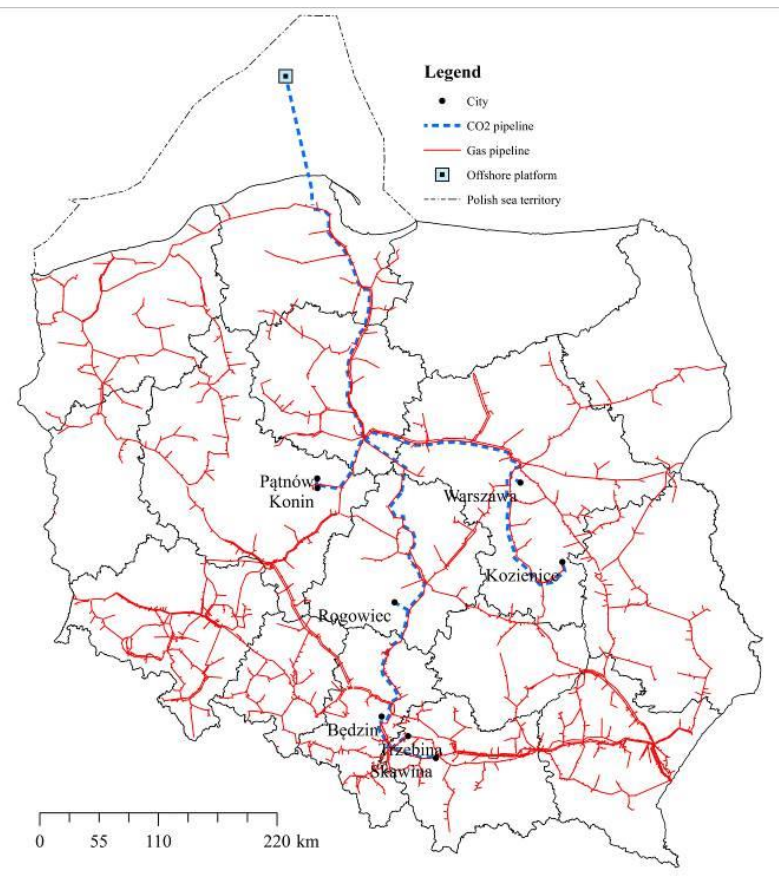

Fig. 4.1. Optimal $\mathrm{CO}_{2}$ transport route regarding infrastructure CAPEX.

The selection of $\mathrm{CO}_{2}$ sources was made by taking into account the flow weighted unit cost of transport infrastructure $\left(\right.$ per $\mathrm{m}^{3} / \mathrm{h}$ ) required for each power plant. Power plants with high costs were discarded and the choice was made among the ones with low values, having in mind that total power output of the selected units should contribute towards $32 \%$ in total national power generation capacity. Infrastructure design procedure described above was again employed for this scenario followed by diameter sizing calculations resulting in technical specification of the infrastructure as presented in Tables 4.1 and 4.2.

Annual amount of transported $\mathrm{CO}_{2}$ is $168460305 \mathrm{~m}^{3}$ which is $95 \mathrm{MT}$. Storage site capacity is $\sim 900$ MT [17] which gives for this case scenario 9 years of operational time under full load conditions of power plants. Total CAPEX is 612.6 M€. 
Table 4.1. Infrastructure costs for specific branches.

\begin{tabular}{|c|c|c|c|c|c|}
\hline \multicolumn{6}{|c|}{ Main branch } \\
\hline Power Plant No. & $\begin{array}{c}\mathrm{CO}_{2} \text { stream } \\
\left(\mathbf{m}^{3} / \mathbf{h}\right)\end{array}$ & $\begin{array}{c}\text { Length } \\
(\mathbf{k m})\end{array}$ & DN & $\begin{array}{l}\text { Pipeline } \\
\text { cost } \\
\text { (M€) }\end{array}$ & $\begin{array}{c}\text { Cost incl. } \\
\text { assembly } \\
\text { works (M€) }\end{array}$ \\
\hline$(16+12+11+1)+(9+15+18)+(2+14)$ & 19231 & 252 & 650 & 98.7 & 328.9 \\
\hline \multicolumn{6}{|c|}{ Skawina - Rogowiec branch } \\
\hline 16 & 675 & 41 & 150 & 3.6 & 12.1 \\
\hline 12 & 1022 & 21 & 200 & 2.5 & 8.4 \\
\hline $12+16$ & 1697 & 2 & 250 & 0.3 & 1.0 \\
\hline 11 & 1258 & 5 & 200 & 0.6 & 2.0 \\
\hline $16+12+11$ & 2955 & 130 & 300 & 24.0 & 79.9 \\
\hline 1 & 8127 & 15 & 450 & 4.0 & 13.3 \\
\hline $16+12+11+1$ & 11082 & 31 & 500 & 9.2 & 30.8 \\
\hline \multicolumn{6}{|c|}{ Pątnów - Konin branch } \\
\hline $9+15$ & 2568 & 9 & 250 & 1.4 & 4.6 \\
\hline 18 & 304 & 3 & 150 & 0.3 & 0.9 \\
\hline $9+15+18$ & 2872 & 19 & 300 & 3.5 & 11.7 \\
\hline \multicolumn{6}{|c|}{ Kozienice - Ostrolęka branch } \\
\hline 2 & 4326 & 150 & 350 & 30.6 & 101.9 \\
\hline 14 & 951 & 11 & 200 & 1.3 & 4.4 \\
\hline $2+14$ & 5277 & 19 & 350 & 3.9 & 12.9 \\
\hline
\end{tabular}

Table 4.2. Power plants individual CAPEX.

\begin{tabular}{|c|c|c|}
\hline Power Plant & Total cost $\mathbf{( M € )}$ & Flow weighted unit cost EUR/(m $\mathbf{3} / \mathbf{h})$ \\
\hline Rogowiec & 174.9 & 4415 \\
\hline Kozienice & 186.5 & 26005 \\
\hline Pątnów & 58.9 & 5850 \\
\hline Warszawa & 23.0 & 7060 \\
\hline Konin & 7.3 & 6973 \\
\hline Będzin & 61.0 & 31390 \\
\hline Trzebinia & 56.9 & 38605 \\
\hline Skawina & 44.1 & 48295 \\
\hline
\end{tabular}

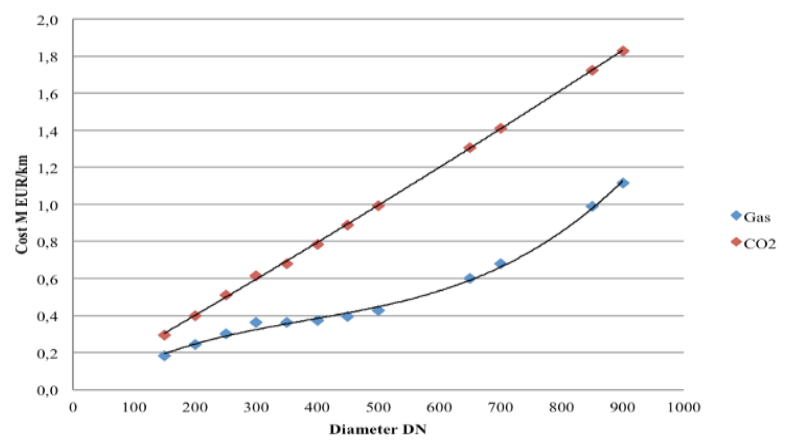

Fig. 4.1. Comparison between natural gas and $\mathrm{CO}_{2}$ pipeline costs incl. assembly works.

The estimation of $\mathrm{CO}_{2}$ pipeline infrastructure cost cannot be achieved based on natural gas infrastructure data. The difference lays in maximum operating pressure (MOP) of the pipelines, which in turn determine the pipe wall thickness. The $\mathrm{CO}_{2}$ networks will be operated under much higher MOP compared to onshore natural gas networks currently operated by Polish transmission system operator, which leads to an increased material cost due to greater pipe wall thickness. These differences in costs are presented in Figure 4.1 


\section{Summary}

The operational time for selected geological structure is too short to consider it as a longterm delivery storage site despite fulfilling physical criteria for $\mathrm{CO}_{2}$ storage. In order to accommodate future capacity additional onshore storage locations, or preferably supra-national scale offshore transport network as proposed in [22], should be considered. Future, detailed calculations of the pipeline options should be on a GIS platform with the help of 3D spatial analysis and consideration of terrain factors, and should also include the costs of compression facilities.

\section{References}

1. European Commission. Energy Roadmap 2050 (2011)

2. M.M.J. Knoope, A. Ramírez, A.P.C. Faaij, Int. J. Green. Gas Cont. 16, 241-70 (2013)

3.M.K. Chandel, L.F. Pratson, E. Williams, Energy Convers. Manage. 51, 12, 2825-34 (2010)

4. G.F. Weihs, D.E. Wiley, Int. J. Green. Gas Cont. 8, 150-168 (2012)

5. U. Zahid, U. Lee, J. An, Y. Lim, C. Han, Environ. Prog. Sust. Energy 33, 978-92 (2014)

6. J.Y. Jung, C. Huh, S.G. Kang, Y. Seo, D. Chang, Appl. Energy 111, 1054-60 (2013)

7. T. Suzuki, M. Toriumi, T. Sakemi, N. Masui, S. Yano, H. Fujita, H. Furukawa, Energy Proced. 37, 2989-2996 (2013)

8. P. Jain, K. Pathak, S. Tripathy, Energy Proced. 37, 3233-3241 (2013)

9. N. Elahi, N. Shah, A. Korre, S. Durucan, Energy Proced. 63, 2655-62 (2014)

10. X. Luo, M. Wang, E. Oko, C. Okezue, Appl. Energy 132, 610-20 (2014)

11. J. Hetland, J. Barnett, A. Read, J. Zapatero, J. Veltin, Energy Proced. 63, 2458-66 (2014)

12. B. Bai, X. Li, Y. Yuan, D. Zhou, P. Li, Acta Geotech. 9, 1, 115-26 (2014)

13. C. Han, U. Zahid, J. An, K. Kim, C. Kim, Curr. Opin. Chem. Eng. 10, 42-8 (2015)

14. M. Chaczykowski, A.J. Osiadacz, Int. J. Green. Gas Cont. 9, 446-56 (2012)

15. B. Wetenhall, J.M. Race, M.J. Downie, Int. J. Green. Gas Cont. 30, 197-211 (2014)

16. M. Witek, J. Nat. Gas Sci. Eng. 27, 374-84 (2015)

17. Polish Geological Institute. Assessment of Formations and Structures Suitable for Safe $\mathrm{CO}_{2}$ Geological Storage Including the Monitoring Plans. Final report. (2013) (in Polish)

18. H. Mahgerefteh, G. Denton, Y. Rykov, Institution of Chemical Engineers Symposium Series 154, 869 (2008)

19. A. Ghasemkhani, A. Anvari-Moghaddam, J.M. Guerrero, B. Bak-Jensen, Proceedings of IEEE PES Innovative Smart Grid Technologies (ISGT, 2016)

20. M. Chaczykowski, A.J. Osiadacz, Arch. Min. Sci. 57, 1, 23-38 (2012)

21. E. Mechleri, S. Brown, P.S. Fennell, N. Mac Dowell, Chem. Eng. Res. Des. 119, 130-9 (2017)

22. R.J. Stewart, V. Scott, R.S. Haszeldine, D. Ainger, S. Argent, Gren. Gases: Sci. Technol. 4, 4, 481-94 (2014) 